\title{
Knockdown of miR-194-5p inhibits cell proliferation, migration and invasion in breast cancer by regulating the Wnt/ $\beta$-catenin signaling pathway
}

\author{
FEIBIAO YANG, ZHANGSHENG XIAO and SONGZE ZHANG
}

Department of Thyroid and Breast Surgery, Yinzhou People's Hospital of Ningbo City, Ningbo, Zhejiang 315040, P.R. China

Received January 5, 2018; Accepted September 17, 2018

DOI: 10.3892/ijmm.2018.3897

\begin{abstract}
Breast cancer is a major public health concern, due to its increasing incidence and limited effective treatment. The present study aimed to investigate the expression of microRNA (miR)-194-5p and its roles in breast cancer. The expression levels of miR-194-5p and SRY-box 17 (SOX17) mRNA were detected in breast cancer tissues and cell lines by reverse transcription-quantitative polymerase chain reaction. The protein expression levels were determined by western blotting. In addition, MTT, colony formation, scratch and Transwell assays were use to evaluate the characteristics of MCF-7 cells with miR-194-5p knockdown. The target verification of miR-194-5p was determined by luciferase reporter assay. Furthermore, tumor-bearing nude mice with miR-194-5p knockdown were used to assess the effects of miR-194-5p on tumor activity. In breast cancer tissues, miR-194-5p was upregulated, whereas SOX17 was downregulated. In addition, the expression levels of SOX17 and phosphorylated (p)- $\beta$-catenin in the cytosol and nucleus were increased in the miR-194-5p inhibitor group. In addition, cell proliferation, migration and invasion were inhibited in response to miR-194-5p knockdown. The luciferase reporter assay confirmed that SOX17 was a target gene of miR-194-5p. In the mouse studies, knockdown of miR-194-5p suppressed tumor growth and promoted SOX17 expression in nude mice with breast cancer. These findings suggested that knockdown of miR-194-5p may increase the expression of SOX17 and regulate the Wnt/ $\beta$-catenin signaling pathway in breast cancer cells; therefore, miR-194-5p may be considered a potential target for breast cancer prevention.
\end{abstract}

\section{Introduction}

It has been reported that the incidence of breast cancer is increasing, and it is predicted to increase further in the next

Correspondence to: Mr. Feibiao Yang, Department of Thyroid and Breast Surgery, Yinzhou People's Hospital of Ningbo City, 251 Baizhang East Road, Ningbo, Zhejiang 315040, P.R. China

E-mail: yangfb670@yeah.net

Key words: breast cancer, SOX17, miR-194-5p, Wnt/ $\beta$-catenin, migration, invasion
20 years worldwide (1). Substantial evidence has suggested that risk factors, including genetic mutations, family inheritance, chemicals, radiation and lifestyle factors, such as being overweight, excessive alcohol consumption and insufficient physical exercise, contribute to the high incidence of breast cancer (2). Breast cancer is a solid tumor, and the surrounding tumor microenvironment is particularly important for its development (3). Furthermore, expression of the estrogen receptor, progesterone receptor or the human epidermal growth factor receptor 2 oncogene is a significant indicator for breast cancer classification (4). Recently, breast cancer treatment has markedly improved due to advances in chemotherapy, including anthracyclines, alkylating agents and cytoskeletal disruptors; radiation therapy; hormonal blockade, including tamoxifen and aromatase inhibitors; and targeted biological therapies, including trastuzumab and lapatinib. However, the side effects of various therapies, including the risk of cardiovascular diseases and breast cancer recurrence remain complex issues that urgently need to be addressed (5).

MicroRNAs (miRNAs/miRs) are a class of non-coding RNA molecules, 18-24 nucleotides long, which regulate gene expression at the post-transcriptional level by specifically binding to their targets (6). Various miRNAs, including miR-206, miR-221/222, miR-22, let-7 family, miR-34 and miR-194 serve regulatory roles in breast cancer progression (7). Furthermore, miR-194 is a vertebrate-specific miRNA, which has pivotal roles in energy production, inflammatory inhibition and malignancies, such as breast cancer, non-small cell lung cancer (8), renal cell carcinoma (9), acute myeloid leukemia (10) and colorectal cancer (11). Furthermore, upregulation of miR-194 is associated with the recurrence of breast cancer (12). However, the exact roles of miR-194 in breast cancer remain to be elucidated.

The Wnt/ $\beta$-catenin pathway is a complex signaling cascade, which serves significant biological roles in embryonic development, cellular polarity, cell proliferation, differentiation and apoptosis (13). Wnt ligands are able to interact with the Frizzled family of seven-pass transmembrane receptors, and/or co-receptors, such as lipoprotein receptor-related protein 5/6, receptor tyrosine kinase like orphan receptor 2 and receptor-like tyrosine kinase. Subsequently, activation of the Wnt pathway leads to the accumulation of $\beta$-catenin in the nucleus. The binding reaction of $\beta$-catenin to $\mathrm{T}$ cell factor/lymphoid enhancer factor (LEF) gives rise to gene expression (14). The 
Wnt/ $\beta$-catenin signaling pathway is associated with regulation of a wide range of biological effects, due to its ability to up- or downregulate downstream gene expression, thus resulting in the alteration of other signaling pathways (15). SRY-box 17 (SOX17) belongs to the high-mobility group-box transcription factor family. It has been reported that SOX17 gene methylation in breast cancer may promote the degradation of $\beta$-catenin in the Wnt singling pathway (16). However, the roles of SOX17 in breast cancer remain to be determined.

The present study aimed to investigate the expression of miR-194-5p and its roles in breast cancer. To verify that SOX17 is a direct target gene of miR-194-5p, bioinformatics analysis using TargetScan (http://www.targetscan.org/vert_71/) indicated that SOX17 is a direct target of miR-194-5p. Therefore, the present study investigated the correlation between miR-194-5p and SOX17, and the biological effects of miR-194-5p knockdown on the $\mathrm{Wnt} / \beta$-catenin signaling pathway in breast cancer.

\section{Materials and methods}

Tissues and cells. The human studies were approved by the ethics committee of Yinzhou People's Hospital of Ningbo City (Ningbo, China). Written informed consent was obtained from all patients. A total of 30 pairs of breast cancer and paracarcinoma tissues ( $\geq 5 \mathrm{~cm}$ away from the tumor edge) were obtained from patients with breast cancer that had not undergone radiotherapy and chemotherapy (age range, 25-55 years old). The patients were admitted to the Yinzhou People's Hospital of Ningbo City between January 2015 and March 2017. After tissue collection, the specimens were fixed at $4{ }^{\circ} \mathrm{C}$ overnight in $10 \%$ formalin for storage. The normal breast epithelial cell line MCF-10A, and the breast cancer cell lines, MCF-7, T47D and MDA-MB-231, were obtained from the American Type Culture Collection (Manassas, VA, USA). All cells were cultured in Roswell Park Memorial Institute-1640 medium supplemented with $10 \%$ fetal bovine serum (FBS) (both from Gibco; Thermo Fisher Scientific, Inc., Waltham, MA, USA).

Reverse transcription-quantitative polymerase chain reaction $(R T-q P C R)$. RT-qPCR was performed to investigate the correlation between $\mathrm{miR}-194-5 \mathrm{p}$ and SOX17 in breast cancer. Once cells reached $60 \%$ confluence, TRIzol ${ }^{\circledR}$ reagent (Invitrogen; Thermo Fisher Scientific, Inc.) was applied for RNA extraction. The same method was used for RNA extraction from tissues. RNA concentration was determined using a NanoDrop 2000 instrument (NanoDrop Technologies; Thermo Fisher Scientific, Inc., Wilmington, DE, USA). M-MLV RT (cat no. 28025-013; Invitrogen; Thermo Fisher Scientific, Inc.) and GoTaq ${ }^{\circledR}$ DNA Polymerase (cat no. M3005; Promega Corporation, Madison, WI, USA) were used for cDNA synthesis and PCR, respectively. cDNA synthesis was conducted at $95^{\circ} \mathrm{C}$ for $12 \mathrm{~min}$, and the PCR thermocycling conditions were as follows: $97^{\circ} \mathrm{C}$ for $5 \mathrm{~min}$, followed by 35 cycles at $95^{\circ} \mathrm{C}$ for $30 \mathrm{sec}, 65^{\circ} \mathrm{C}$ for $30 \mathrm{sec}$ and $73^{\circ} \mathrm{C}$ for $1 \mathrm{~min}$, and a final step at $73^{\circ} \mathrm{C}$ for $10 \mathrm{~min}$, after which samples were maintained at $4^{\circ} \mathrm{C}$ until use. The miR-194-5p and SOX17 PCR primer sequences were as follows: miR-194-5p, forward, 5'-ACACTCCAGCTGGGTGTA ACAGCA ACT CC-3' and reverse, 5'-TGGTGTCGTGGAGTCG-3'; and SOX17, forward, 5'-GTGGACCGCACGGAATTTG-3' and reverse, 5'-GGAGATTCACACCGGAGTCA-3'. The expression levels were normalized to U6 or GAPDH, the primer sequences were as follows: U6, forward, 5'-AGTAAGCCCTTGCTGTCAG TG-3' and reverse, 5'-CCTGGGTCTGATAATGCTGGG-3'; and GAPDH, forward, 5'-ACAACTTTGGTATCGTGGAAG G-3' and reverse, 5'-GCCATCACGCCACAGTTTC-3'. The $2^{-\triangle \Delta C q}$ method was used for relative quantification (17).

Cell transfection. MCF-7 cells $\left(1 \times 10^{5}\right)$ were seeded into 24-well plates, and the miR-194-5p inhibitor (miR20000460-1-5) and miR-194-5p overexpression plasmids (miR10000460-1-5) were obtained from Guangzhou RiboBio Biotechnology Co., Ltd. (Guangzhou, China). The overexpression plasmid was used for luciferase reporter assays. Briefly, $500 \mathrm{ng}$ plasmids were transfected into cells using $1 \mu 1$ Lipo6000 ${ }^{\mathrm{TM}}$ Transfection Reagent (Beyotime Institute of Biotechnology, Shanghai, China); the cells were incubated at $37^{\circ} \mathrm{C}$ in an atmosphere containing $5 \% \mathrm{CO}_{2}$ for $6 \mathrm{~h}$. Subsequently, the transfected cells were incubated for a further $72 \mathrm{~h}$. The empty vector was transfected into cells in the overexpression negative control (NC) groups. The following sequences were transfected for miR-194-5p overexpression: Forward, 5'-CAGGAGTTGTAAATCCGAGCCG-3' and reverse, 5'-TTCATAGGTCAGAGCCCTGTGCA-3'.

MTT assay. After $72 \mathrm{~h}$ incubation, the MTT assay was performed for cell proliferation analysis. Briefly, MCF-7 cells $\left(5 \times 10^{5}\right.$ cells/well) were placed into 96 -well plates and the cell proliferation rate was determined at various time points $(24,48$ and 72 h). Briefly, $20 \mu \mathrm{l}$ MTT reagent (Sigma-Aldrich; Merck KGaA, Darmstadt, Germany) was added to cells and incubated for $4 \mathrm{~h}$ at $37^{\circ} \mathrm{C}$. Subsequently, formazan crystals were dissolved in dimethyl sulfoxide and the optical density (OD) value was detected at $490 \mathrm{~nm}$ using a microplate reader.

Colony formation assay. The colony formation assay was performed after transfection and $72 \mathrm{~h}$ incubation. Cells (1,500 cells/well) were plated into 12 -well plates and cultured for 10 days to form colonies. The cells were then fixed with methanol for $15 \mathrm{~min}$ at $4^{\circ} \mathrm{C}$ and stained with Giemsa dye solution for $30 \mathrm{~min}$ at room temperature to visualize cell colonies. Images were captured under a light microscope.

Scratch and Transwell assays. Post-transfection, the migration and invasion of MCF-7 cells was evaluated by scratch and Transwell assays. For the scratch assay, MCF-7 cells in log phase were seeded into 96-well plates to obtain a monolayer cell culture. Across the center of the well, the cell monolayer was scratched using a fresh 1-ml pipette tip; the width of the scratch was equal to the outer diameter of the tip. Subsequently, the cells were incubated at $37^{\circ} \mathrm{C}$ in an atmosphere containing $5 \% \mathrm{CO}_{2}$ for $72 \mathrm{~h}$. Images of the migrated cells were captured after $24 \mathrm{~h}$ under an inverted microscope (CKX41; Olympus Corporation, Tokyo, Japan) and were analyzed using ImageJ v1.8.0 (National Institutes of Health, Bethesda, MD, USA). For the Transwell assay, Transwell culture inserts (pore size, $8 \mathrm{~mm}$; Falcon; BD Biosciences, Franklin Lakes, NJ, USA) were placed into the wells of 96-well plates, thus leading to separated upper and lower chambers. The upper side of the membrane was precoated with Matrigel (BD Biosciences) and incubated at $37^{\circ} \mathrm{C}$ for $1 \mathrm{~h}$ for gel formation. FBS was used to hydrate the membrane $2 \mathrm{~h}$ prior to use. Subsequently, 

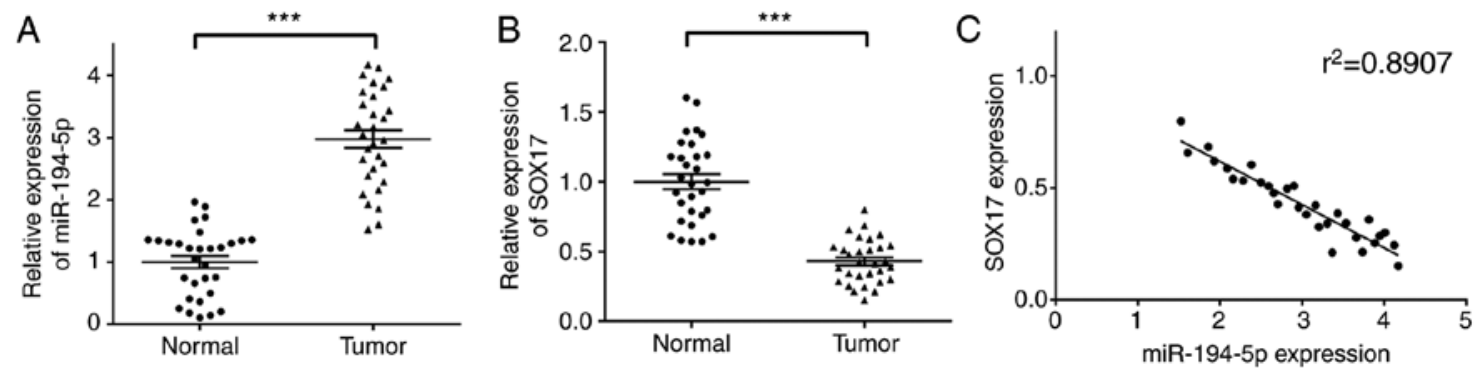

Figure 1. Expression of miR-194-5p and SOX17 in breast cancer tissues, and correlation analysis. The expression levels of (A) miR-194-5p and (B) SOX17 were determined by reverse transcription-quantitative polymerase chain reaction. (C) Pearson's correlation coefficient was employed for correlation analysis. ${ }^{* * *} \mathrm{P}<0.01$. miR-194-5p, microRNA-194-5p; SOX17, SRY-box 17.

Dulbecco's modified Eagle's medium (Gibco; Thermo Fisher Scientific, Inc.; $600 \mu \mathrm{l}$ ) containing $10 \%$ FBS was added to the lower chamber, whereas $1 \times 10^{5}$ cells/well were added to the upper chamber. After $72 \mathrm{~h}$ at $37^{\circ} \mathrm{C}$, the number of invading cells was counted using a counting chamber under an inverted microscope (CKX41; Olympus Corporation).

Western blotting. Western blot analysis was conducted after $72 \mathrm{~h}$ incubation. Proteins were isolated from transfected MCF-7 cells using radioimmunoprecipitation assay lysis buffer (Beyotime Institute of Biotechnology) and protein concentration was measured using a bicinchoninic acid kit (Beyotime Institute of Biotechnology). Cytosolic protein was extracted using the Cytosol Protein Extraction kit (\#P0033; Beyotime Institute of Biotechnology). Nuclear protein was extracted using the Nucleoprotein Extraction kit (\#C500009-0050; Sangon Biotech Co., Ltd., Shanghai, China). Subsequently, the protein samples $(20 \mu \mathrm{g} /$ per lane) were separated by 15\% SDS-PAGE. Polyvinylidene fluoride (PVDF) membranes (EMD Millipore, Billerica, MA, USA) were used for protein transfer. Subsequently, the PVDF membranes were blocked with 5\% skimmed milk for $2 \mathrm{~h}$ at room temperature, and were incubated with the following primary antibodies: Anti-SOX17 (\#81778, 1:2,000), anti-Wnt (\#2915, 1:2,000), anti- $\beta$-catenin (\#8480, 1:500), anti-phosphorylated (p)- $\beta$-catenin (\#9567, 1:500) and anti-GAPDH (\#5174, 1:2,000) (Cell Signaling Technology, Inc., Danvers, MA, USA) for $1 \mathrm{~h}$ at room temperature, followed by incubation with secondary antibodies (sc-2004, 1:1,000; Santa Cruz Biotechnology, Inc., Dallas, TX, USA) for $45 \mathrm{~min}$ at room temperature. An enhanced chemiluminescence kit (\#32209; Pierce; Thermo Fisher Scientific, Inc.) was applied for visualization and the images were analyzed using ImageJ v1.8.0 (National Institutes of Health).

Bioinformatics analysis and luciferase reporter assays. Bioinformatics analysis with TargetScan, and luciferase reporter assays were conducted to verify that SOX17 was a direct target gene of miR-194-5p. For luciferase reporter assays, MCF-7 cells were seeded into 96-well plates at a density of $2 \times 10^{5}$ cells/well and grown to $70 \%$ confluence. Following the implementation of site-directed mutagenesis using the QuikChange Lightning Site-Directed Mutagenesis kit (Guangzhou RiboBio Biotechnology Co., Ltd.), cells were co-transfected with miR-194-5p mimic or miR-194-5p NC for $48 \mathrm{~h}$ at $37^{\circ} \mathrm{C}$ (50 ng; Guangzhou RiboBio Biotechnology Co., Ltd.), and SOX17-3' untranslated region

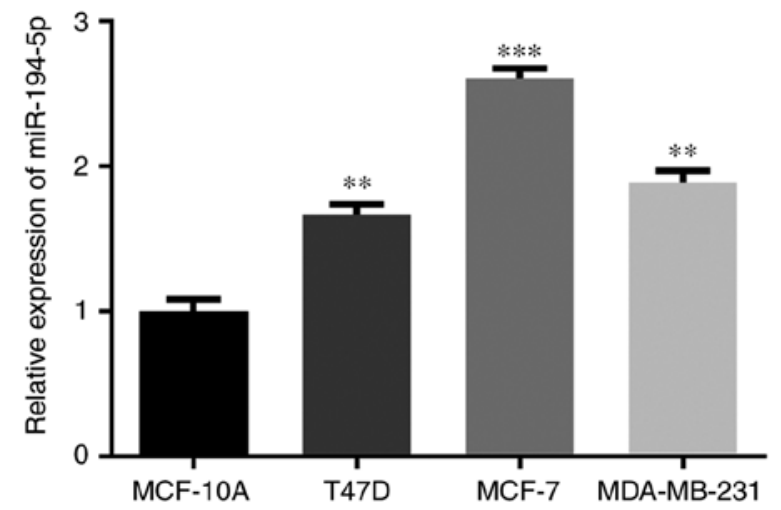

Figure 2. Upregulation of miR-194-5p in various breast cancer cell lines. The expression levels of miR-194-5p in the normal breast epithelial cell line MCF-10A and the breast cancer cell lines were determined by reverse transcription-quantitative polymerase chain reaction. ${ }^{* *} \mathrm{P}<0.01$, ${ }^{* * * *} \mathrm{P}<0.01$ vs. MCF-10A cells. miR-194-5p, microRNA-194-5p.

(UTR)-wild-type (WT) (50 ng) or SOX17-3'UTR-mutant (MUT) $(50 \mathrm{ng}$ ) plasmids (Guangzhou RiboBio Biotechnology Co., Ltd.) using Lipo6000 ${ }^{\mathrm{TM}}$ Transfection Reagent $(0.2 \mu \mathrm{l})$. Furthermore, transfection efficiency was normalized to a Renilla luciferase vector (pRL-CMV; Promega Corporation). The luciferase assay kit (BioLux ${ }^{\circledR}$ Gaussia; New England Biolabs, Inc., Ipswich, MA, USA) was used to evaluate luciferase activity according to the manufacturer's protocol.

Animals. The animal studies were approved by the laboratory animal management and welfare ethical review committee of Yinzhou People's Hospital of Ningbo City. A total of 18 female BALB/c-nu/nu nude mice (age, 4-5 weeks; weight, 18-25 g) were obtained from Zhejiang Experimental Animal Center. The mice were housed in a specific pathogen-free laboratory and were maintained under the following conditions: Constant temperature, $22-26^{\circ} \mathrm{C}$; humidity, $40-70 \%$; $12-\mathrm{h}$ light/dark cycle; free access to food and water). Briefly, the mice were randomly divided into groups $\mathrm{A}$ and $\mathrm{B}$; mice in group A were used for tumor weight and volume analysis, whereas mice in group B were used for immunohistochemical analysis. Briefly, $500 \mathrm{ng} \mathrm{miR}-194-5 \mathrm{p}$ inhibitor and negative control (NC) were transfected into MCF-7 cells with $1 \mu \mathrm{l}$ Lipo6000 $0^{\mathrm{TM}}$ Transfection Reagent at $37^{\circ} \mathrm{C}$ with $5 \% \mathrm{CO}_{2}$ for $6 \mathrm{~h}$. Subsequently, $1 \times 10^{7} / 0.3 \mathrm{ml}$ MCF-7 cells in the log phase were inoculated into the left side of the breast to generate a murine model of breast cancer. After 20 days ad libitum 
A

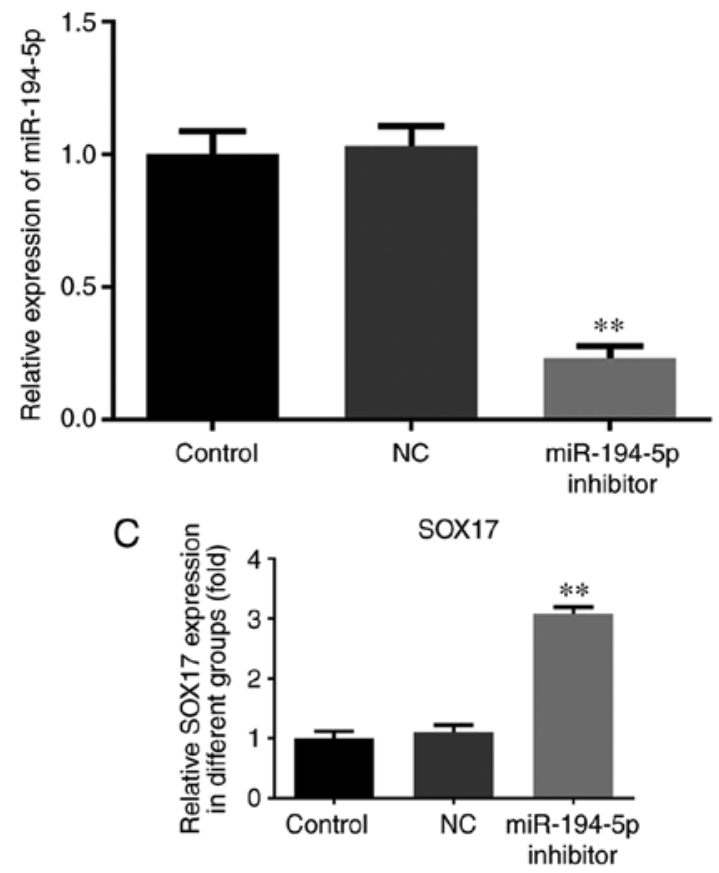

B

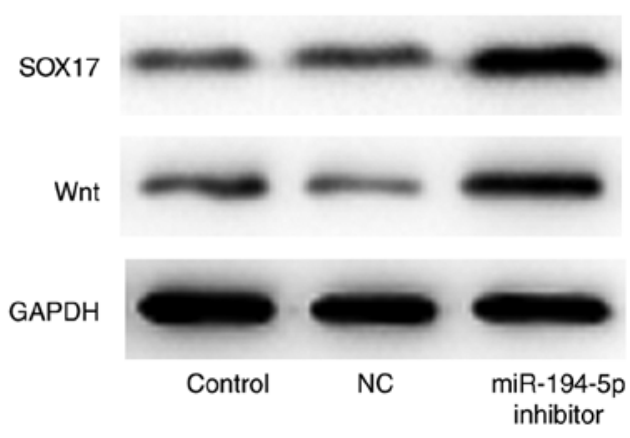

Wnt

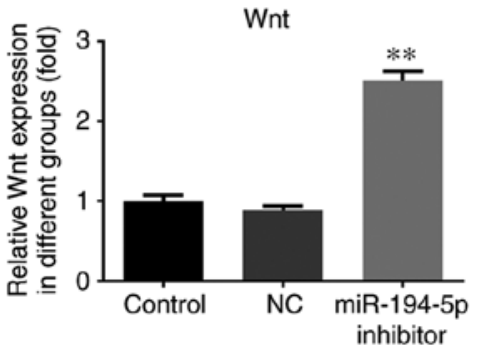

Figure 3. Knockdown of miR-194-5p promotes SOX17 and Wnt expression in MCF-7 cells. (A) Expression levels of miR-194-5p in untransfected or transfected MCF-7 cells were determined by reverse transcription-quantitative polymerase chain reaction. (B) Western blot analysis of SOX17 and Wnt. (C) Semi-quantitative analysis of SOX17 and Wnt. ${ }^{* *} \mathrm{P}<0.01$, compared with the NC group. miR-194-5p, microRNA-194-5p; NC, negative control; SOX17, SRY-box 17.

feeding, the tumor-burdened nude mice exhibited tumors $\sim 0.5 \mathrm{~cm}$ in diameter. Mice were divided into the control, NC and miR-194-5p inhibitor groups.

Tumor weight and size. Tumor weight was measured using an electric scale and tumor volume was recorded using a vernier caliper 20 days after MCF-7 cell inoculation.

Immunohistochemistry(IHC). After 20 days ad libitum feeding, the mice were anesthetized and sacrificed. Subsequently, the tumor tissues were obtained and fixed in $10 \%$ formalin at $4^{\circ} \mathrm{C}$ overnight. Sections were incubated with anti-SOX17 primary antibodies (\#81778S, 1:1,000; Cell Signaling Technology, Inc.) for $1 \mathrm{~h}$ at room temperature, after which they were incubated with secondary antibodies (\#7074, 1:2,000; Cell Signaling Technology, Inc.) for $10 \mathrm{~min}$ at room temperature. Images of staining were captured under an inverted microscope (CKX41; Olympus Corporation) and were analyzed using Image-Pro Plus 6.0 (Media Cybernetics, Inc., Rockville, MD, USA).

Statistical analysis. Each experiment was repeated in triplicate and all data are presented as the means \pm standard deviation. Additionally, Student's t-test was used for two group comparisons, whereas one-way analysis of variance followed by the Dunnett's post hoc test was used for multiple group comparisons, and the Pearson's correlation coefficient was employed for correlation analysis. Data were analyzed using SPSS 14.0 (SPSS, Inc., Chicago, IL, USA). P $<0.05$ was considered to indicate a statistically significant difference.

\section{Results}

Expression levels of miR-194-5p and SOX17 in breast cancer tissues, and correlation analysis. In order to investigate the correlation between miR-194-5p and SOX17 in breast cancer, the expression levels of miR-194-5p and SOX17 were determined by RT-qPCR. As shown in Fig. 1A and B, miR-194-5p was significantly upregulated, whereas SOX17 was markedly downregulated in breast cancer tissues compared with in normal tissues. In addition, a negative correlation was detected between miR-194-5p and SOX17 $\left(\mathrm{r}^{2}=0.8907\right.$; Fig. 1C), thus indicating that the expression of miR-194-5p was negatively correlated with SOX17 in breast cancer. It is of great significance to further elucidate the correlation between miR-194-5p and SOX17, and the regulatory relationship of the Wnt signaling pathway.

Upregulation of miR-194-5p in various breast cancer cell lines. The expression levels of miR-194-5p were also detected in numerous breast cancer cell lines, in order to select an appropriate cell line for subsequent experiments. As shown in Fig. 2, miR-194-5p was significantly increased in MCF-7, T47D and MDA-MB-231 cells compared with in MCF-10A cells. Furthermore, miR-194-5p was most upregulated in MCF-7 cells; therefore, MCF-7 was chosen as the target cell line in the present study.

Knockdown of miR-194-5p promotes SOX17 and Wnt expression in MCF-7 cells. The expression levels of miR-194-5p were measured by RT-qPCR, and the protein expression levels of SOX17 and Wnt in transfected MCF-7 cells were determined by western blotting. As shown in Fig. 3A, the expression levels of miR-194-5p were markedly decreased in the miR-194-5p inhibitor group compared with in the control groups. Furthermore, the expression levels of SOX17 and Wnt were upregulated in the miR-194-5p inhibitor-transfected group compared with in the control groups (Fig. 3B and C). Therefore, knockdown of miR-194-5p in MCF-7 cells may promote the expression of SOX17. 
A

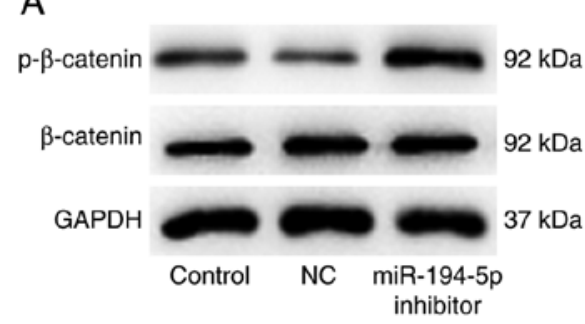

C

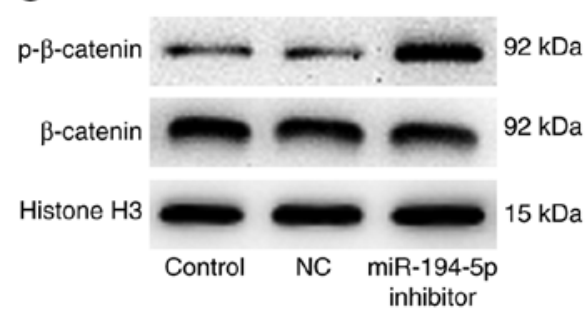

B
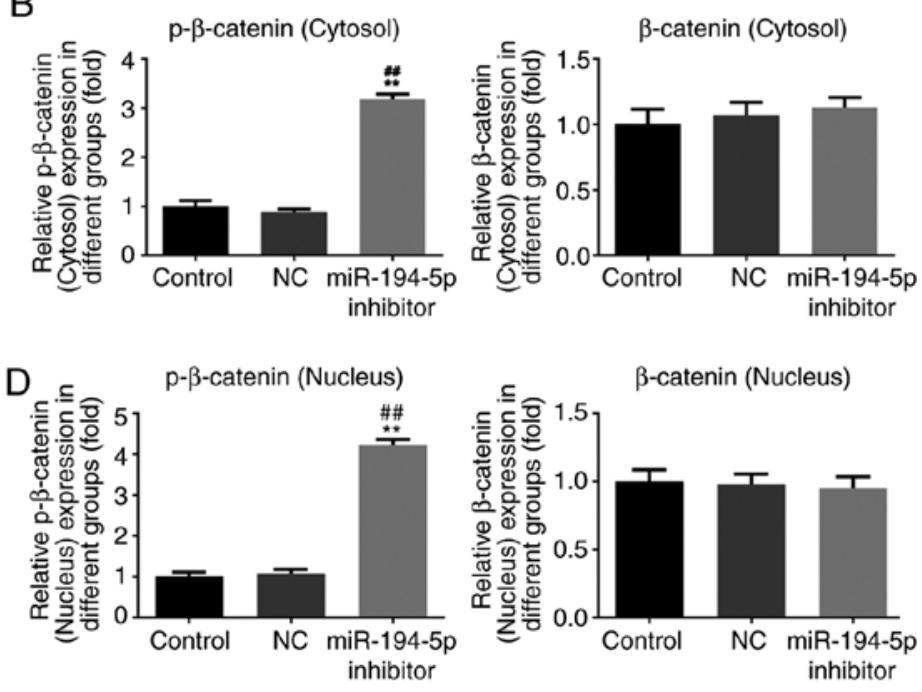

Figure 4. Knockdown of miR-194-5p upregulates the cytosolic and nuclear protein expression of p- $\beta$-catenin in MCF-7 cells. (A) Western blot analysis of $\mathrm{p}-\beta$-catenin and $\beta$-catenin in the cytosol. (B) Semi-quantitative analysis of $\mathrm{p}-\beta$-catenin and $\beta$-catenin in the cytosol. (C) Western blot analysis of p- $\beta$-catenin and $\beta$-catenin in the nucleus. (D) Semi-quantitative analysis of $\mathrm{p}-\beta$-catenin and $\beta$-catenin in the nucleus. ${ }^{* *} \mathrm{P}<0.01$, compared with the $\mathrm{NC}$ group; ${ }^{\# \#} \mathrm{P}<0.001$, compared with the control group. miR-194-5p, microRNA-194-5p; NC, negative control; p- $\beta$-catenin, phosphorylated- $\beta$-catenin.
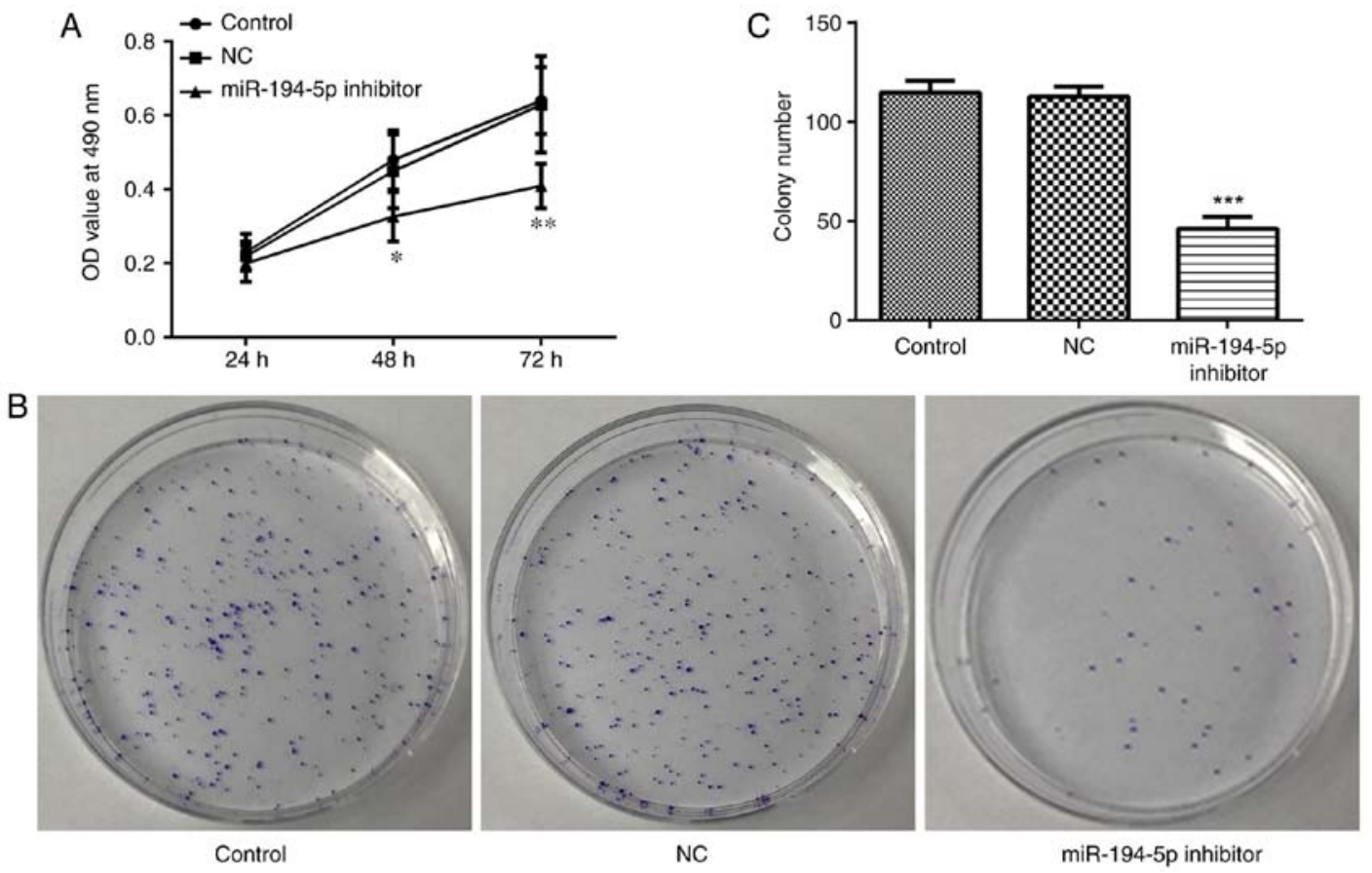

Figure 5. Knockdown of miR-194-5p suppresses the proliferation of MCF-7 cells, as determined by MTT and colony formation assays. (A) MTT and (B) colony formation assays were performed to measure cell proliferation. (C) Colony formation assay was quantitatively analyzed. ${ }^{*} \mathrm{P}<0.05,{ }^{* * *} \mathrm{P}<0.01,{ }^{* * * *} \mathrm{P}<0.01$, compared with the NC group. miR-194-5p, microRNA-194-5p; NC, negative control; OD, optical density.

Knockdown of miR-194-5p upregulates the expression of $p$ - $\beta$-catenin in the cytosol and nucleus of MCF-7 cells. The cytosolic and nuclear protein expression levels of $\mathrm{p}-\beta$-catenin and $\beta$-catenin were also evaluated by western blotting. The results demonstrated that $\mathrm{p}-\beta$-catenin was significantly upregulated in the cytosol and nucleus in the miR-194-5p inhibitor group compared with in the control groups. However, there was no difference in the expression levels of $\beta$-catenin in the cytosol and nucleus between the miR-194-5p inhibitor group and the control groups (Fig. 4). Therefore, knockdown of miR-194-5p in MCF-7 cells might facilitate the expression of p- $\beta$-catenin in the cytosol and nucleus, with no effects on $\beta$-catenin expression.

Knockdown of miR-194-5p suppresses the proliferation of MCF-7 cells. The MTT assay was performed to assess proliferation of miR-194-5p inhibitor-transfected MCF-7 cells. The proliferation rate was determined by OD values. As shown in Fig. 5A, proliferation was significantly decreased in the miR-194-5p inhibitor group compared with in the control groups. As presented in Fig. 5B and C, the proliferation rate 


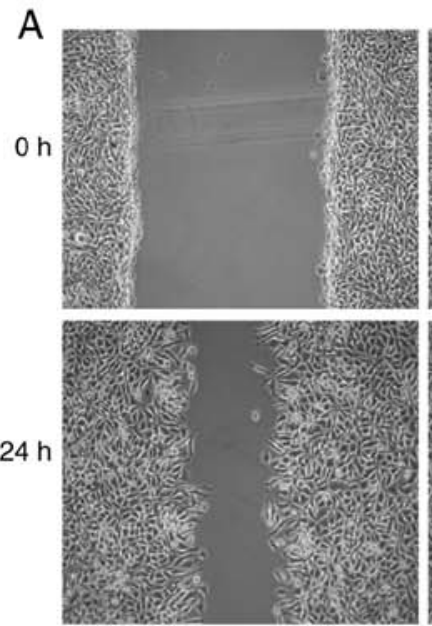

Control

B

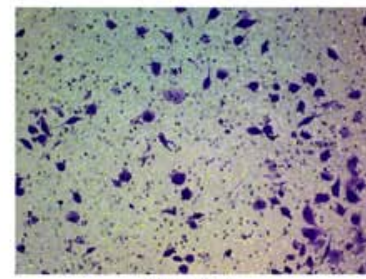

Control
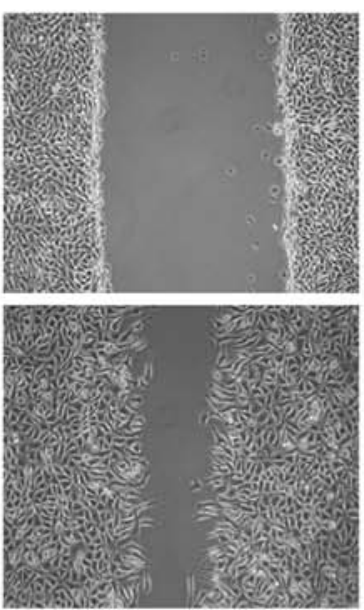

NC

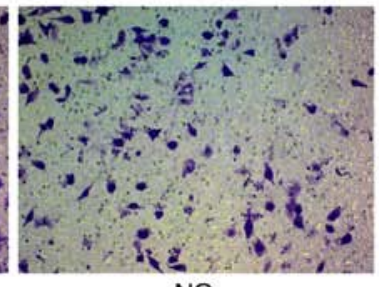

NC

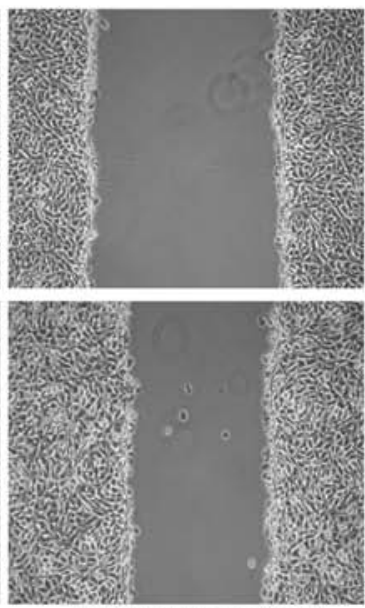

miR-194-5p inhibitor

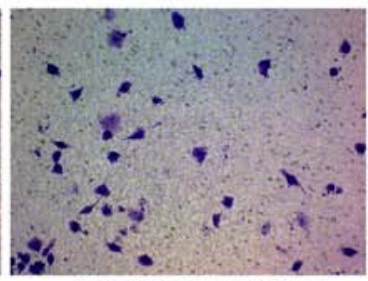

miR-194-5p inhibitor
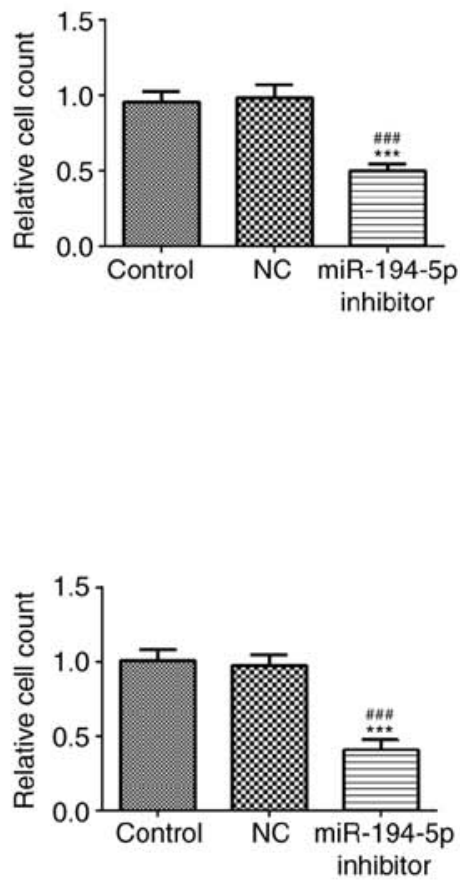

Figure 6. Knockdown of miR-194-5p inhibits the migration and invasion of MCF-7 cells, as determined by scratch and Transwell assays. (A) Migration of MCF-7 cells was detected by scratch assay. (B) Invasion of MCF-7 cells was detected by Transwell assay. Magnification, $\mathrm{x} 200$. ${ }^{* * *} \mathrm{P}<0.01$, compared with the NC group; ${ }^{\# \#} \mathrm{P}<0.001$, compared with the control group. miR-194-5p, microRNA-194-5p; NC, negative control.

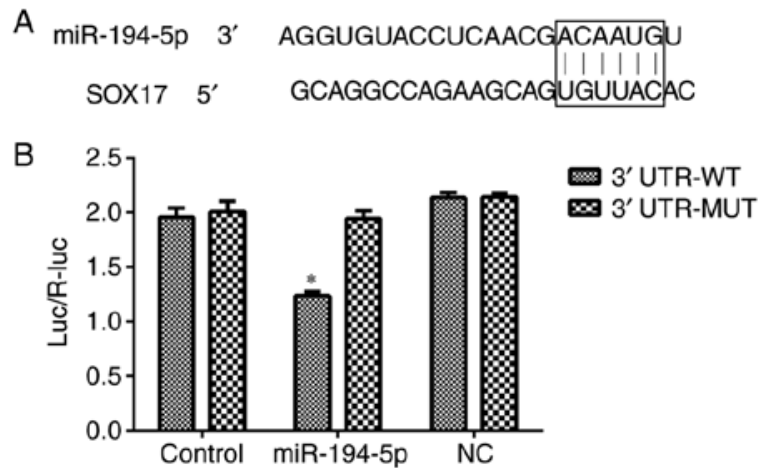

Figure 7. SOX17 is a target gene of miR-194-5p. (A) SOX17 was predicted as the target gene of miR-194-5p by TargetScan. (B) Luciferase reporter assay was performed to verify that SOX17 was a target gene of miR-194-5p. ${ }^{*} \mathrm{P}<0.05$, compared with the UTR-MUT miR-194-5p group. miR-194-5p, microRNA-194-5p; MUT, mutant; NC, negative control; SOX17, SRY-box 17; UTR, untranslated region; WT, wild-type.

was further determined by colony formation assay. The results indicated that proliferation was significantly decreased in the miR-194-5p inhibitor group. These results suggested that knockdown of miR-194-5p may suppress the proliferation of MCF-7 cells.

Knockdown of miR-194-5p inhibits the migration and invasion of MCF-7 cells. The migration and invasion of transfected MCF-7 cells were measured by scratch and Transwell assays, respectively. As shown in Fig. 6A and B, cell migration and invasion were significantly inhibited in the miR-194-5p inhib- itor group compared with in the control groups. Therefore, knockdown of miR-194-5p in MCF-7 cells might inhibit cell migration and invasion.

Luciferase reporter assay for target verification. The results of a TargetScan analysis suggested that SOX17 was a target gene of miR-194-5p, due to a complementary binding region in its 3'UTR. A luciferase reporter assay was performed to verify this prediction. As shown in Fig. 7, luciferase activity was decreased in the SOX17 3'UTR WT group transfected with miR-194-5p mimics, thus suggesting that SOX17 may be a direct target gene of miR-194-5p.

Knockdown of miR-194-5p inhibits tumor growth in nude mice. A total of 20 days after injection with miR-194-5p inhibitor-transfected cells, tumor growth was measured according to tumor volume and weight. As shown in Fig. 8, tumor volume and weight were significantly decreased in the miR-194-5p inhibitor group compared within the control groups. These findings indicated that knockdown of miR-194-5p may contribute to tumor growth suppression in breast cancer.

Knockdown of miR-194-5p promotes SOX17 expression. SOX17 expression was measured by IHC after injection with miR-194-5p inhibitor-transfected cells for 20 days. The results indicated that the expression levels of SOX17 were markedly increased in the miR-194-5p inhibitor group compared with in the control groups (Fig. 9). Therefore, knockdown of miR-194-5p may give rise to the upregulation of SOX17 in breast cancer tissues. 

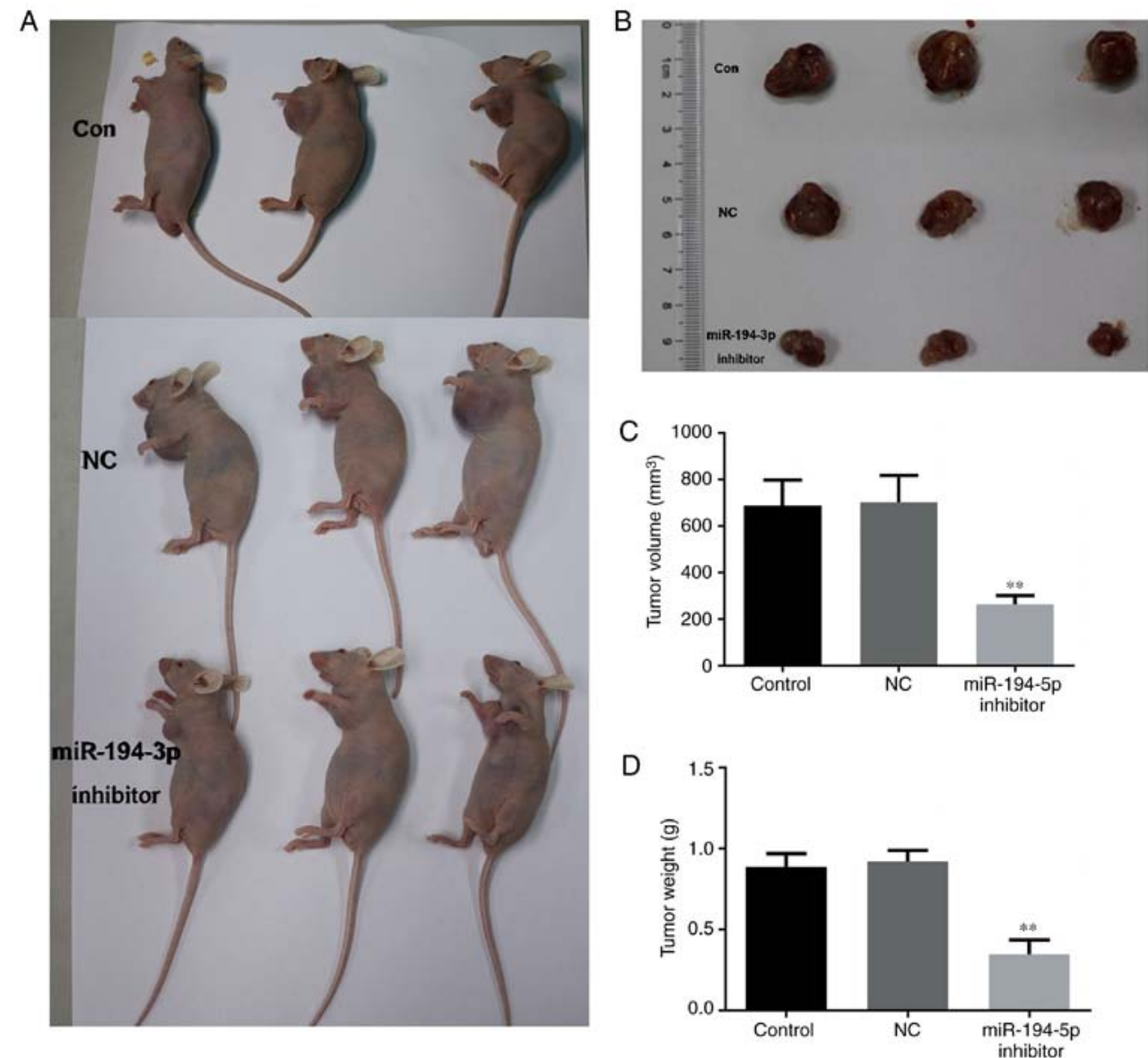

Figure 8. Knockdown of miR-194-5p inhibits tumor growth in nude mice. General conditions of (A) nude mice and (B) tumors in the three groups. (C) Tumor volume and (D) weight of nude mice in the three groups. ${ }^{* *} \mathrm{P}<0.01$, compared with the NC group. miR-194-5p, microRNA-194-5p; NC, negative control.

A
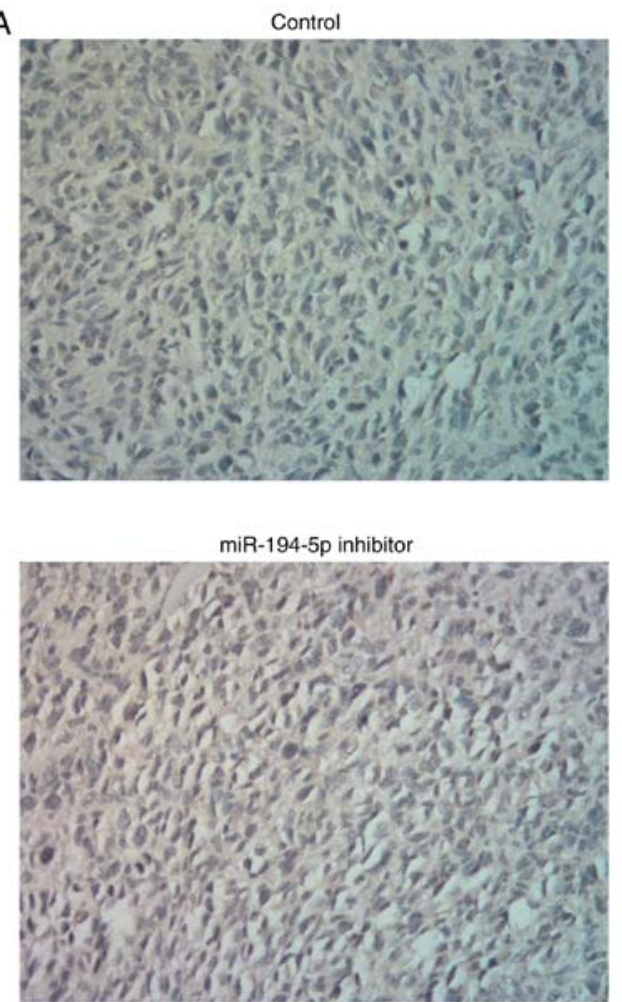

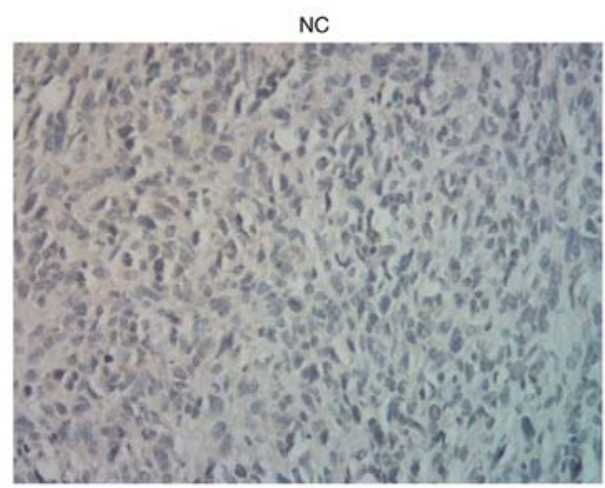

B

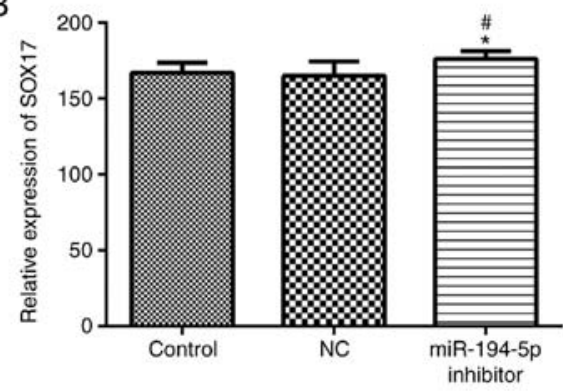

Figure 9. Knockdown of miR-194-5p promotes SOX17 expression, as determined by IHC. (A) IHC was performed to measure SOX17 expression. Magnification, x100. (B) Semi-quantitative analysis of SOX17 expression. " $\mathrm{P}<0.01$, compared with the NC group; ${ }^{*} \mathrm{P}<0.01$, compared with the control group. IHC, immunohistochemistry; miR-194-5p, microRNA-194-5p; NC, negative control; SOX17, SRY-box 17. 


\section{Discussion}

The present study investigated the effects of miR-194-5p knockdown on SOX17 and the Wnt/ $\beta$-catenin signaling pathway in breast cancer. The results demonstrated that miR-194-5p was upregulated in breast cancer, which is consistent with the previous findings by Huo et al (18). In a previous study, the SOX family was confirmed as a target of miR-194, and it was revealed that the expression of SOX is regulated by miR-194 (19). In the present study, SOX17 was identified as a target gene of miR-194-5p. Subsequently, knockdown of miR-194-5p resulted in the upregulation of SOX17. The present study demonstrated that miR-194-5p knockdown upregulated the expression levels of Wnt and $\mathrm{p}-\beta$-catenin in MCF7 cells. An increase in $\mathrm{p}-\beta$-catenin by miR-194-5p knockdown may result in reduced activation of the Wnt/ $\beta$-catenin pathway. Furthermore, miR-194-5p knockdown increased the expression of SOX17, which may have led to inhibition of the $\mathrm{Wnt} / \beta$-catenin signaling pathway; however, increased Wnt expression indicated that this inhibition may involve regulation of other factors. Therefore, knockdown of miR-194-5p may have multiple effects on the Wnt/ $\beta$-catenin pathway.

Numerous studies have reported that SOX17 is an important tumor suppressor in various types of cancer, which can modulate the $\mathrm{Wnt} / \beta$-catenin signaling pathway by binding to LEF (20-23). In addition, the interaction between SOX17 and LEF leads to the reduced combination of SOX17 to $\beta$-catenin, which further results in suppression of the $\mathrm{Wnt} / \beta$-catenin signaling pathway. The $\mathrm{Wnt} / \beta$-catenin signaling pathway is closely associated with numerous types of cancer due to overactivated $\mathrm{Wnt} / \beta$-catenin $(24,25)$. Furthermore, it has been reported that blockade of the $\mathrm{Wnt} / \beta$-catenin signaling pathway could effectively suppress breast cancer metastasis, invasion and cell proliferation (26-29). The present study revealed that knockdown of miR-194-5p inhibited cell proliferation, migration and invasion of MCF-7 cells, which is in concordance with these previous findings. Although the direct regulatory mechanism of miR-194-5p knockdown on the Wnt/ $\beta$-catenin pathway has not been confirmed, it does seem to affect the activity of the signaling pathway and therefore may have an effect on the Wnt/ $\beta$-catenin pathway. In addition, reduced tumor weight and volume in the miR-194-5p inhibitor group of mice with breast cancer indicated that miR-194-5p knockdown might suppress tumor growth. The results of IHC demonstrated that knockdown of miR-194-5p was able to promote the expression of SOX17 in mice with breast cancer. The results of the present mouse studies were in line with the results of experiments in cells, thus suggesting that miR-194-5p knockdown may be an effective potential therapeutic strategy for breast cancer.

However, the expression of SOX17 and the Wnt/ $\beta$-catenin signaling pathway is complex; therefore, we cannot completely eliminate other forms of the interference, including methylation of SOX17 and the effects of other miRNAs. It has been reported that SOX17 promoter methylation leads to poor survival in breast cancer (30). Additionally, other miRNAs, such as the miR-200 family, miR-141 and miR-26 (31-34), are associated with SOX17 expression and the Wnt/ $\beta$-catenin signaling pathway. Therefore, further experiments should be performed to deeply investigate the association among miR-194-5p, SOX17 and the Wnt/ $\beta$-catenin signaling pathway.

In conclusion, the present results indicated that miR-194-5p inhibitor-induced regulation of SOX17 expression and the Wnt/ $\beta$-catenin signaling pathway suppressed cell proliferation, migration and invasion in breast cancer. Although the exact roles of miR-194-5p and SOX17 in the Wnt/ $\beta$-catenin signaling pathway remain to be elucidated, they may be considered targets for the inhibition and treatment of breast cancer progression.

\section{Acknowledgements}

Not applicable.

\section{Funding}

No funding was received.

\section{Availability of data and materials}

The datasets used and/or analyzed during the current study are available from the corresponding author on reasonable request.

\section{Authors' contributions}

FY designed the research. ZX collected and bred the mice, and conducted animal studies. ZX and SZ performed the experiments. FY and ZX analyzed the data and wrote the manuscript. All authors reviewed the results and approved the final version of the manuscript.

\section{Ethics approval and consent to participate}

The human studies were approved by the ethics committee of Yinzhou People's Hospital of Ningbo City (Ningbo, China). Written informed consent was obtained from all patients. The animal studies were approved by the laboratory animal management and welfare ethical review committee of Yinzhou People's Hospital of Ningbo City.

\section{Patient consent for publication}

Not applicable.

\section{Competing interests}

The authors declare that they have no competing interests.

\section{References}

1. Howell A, Anderson AS, Clarke RB, Duffy SW, Evans DG, Garcia-Closas M, Gescher AJ, Key TJ, Saxton JM and Harvie MN: Risk determination and prevention of breast cancer. Breast Cancer Res 16: 446, 2014.

2. Gray JM, Rasanayagam S, Engel C and Rizzo J: State of the evidence 2017: An update on the connection between breast cancer and the environment. Environ Health 16: 94, 2017.

3. Ward R, Sims AH, Lee A, Lo C, Wynne L, Yusuf H, Gregson H, Lisanti MP, Sotgia F, Landberg G and Lamb R: Monocytes and macrophages, implications for breast cancer migration and stem cell-like activity and treatment. Oncotarget 6: 14687-14699, 2015. 
4. Need EF, Selth LA, Trotta AP, Leach DA, Giorgio L, O'Loughlin MA, Smith E, Gill PG, Ingman WV, Graham JD and Buchanan $\mathrm{G}$ : The unique transcriptional response produced by concurrent estrogen and progesterone treatment in breast cancer cells results in upregulation of growth factor pathways and switching from a luminal a to a basal-like subtype. BMC Cancer 15: 791, 2015.

5. Bodai BI and Tuso P: Breast cancer survivorship: A comprehensive review of long-term medical issues and lifestyle recommendations. Perm J 19: 48-79, 2015.

6. Lages E, Ipas H, Guttin A, Nesr H, Berger F and Issartel JP: MicroRNAs: Molecular features and role in cancer. Front Biosci (Landmark Ed) 17: 2508-2540, 2012.

7. Greene SB, Herschkowitz JI and Rosen JM: Small players with big roles: MicroRNAs as targets to inhibit breast cancer progression. Curr Drug Targets 11: 1059-1073, 2010.

8. Zhu X, Li D, Yu F, Jia C, Xie J, Ma Y, Fan S, Cai H, Luo Q, Lv Z and Fan L: miR-194 inhibits the proliferation, invasion, migration, and enhances the chemosensitivity of non-small cell lung cancer cells by targeting forkhead box A1 protein. Oncotarget 7: 13139-13152, 2016.

9. Okato A, Arai T, Yamada Y, Sugawara S, Koshizuka K, Fujimura L, Kurozumi A, Kato M, Kojima S, Naya Y, et al: Dual strands of pre-miR-149 inhibit cancer cell migration and invasion through targeting FOXM1 in renal cell carcinoma. Int J Mol Sci 18: E1969, 2017.

10. Dell'Aversana C, Giorgio C, D'Amato L, Lania G, Matarese F, Saeed S, Di Costanzo A, Belsito Petrizzi V, Ingenito C, Martens JHA, et al: miR-194-5p/BCLAF1 deregulation in AML tumorigenesis. Leukemia 31: 2315-2325, 2017.

11. Chang HY, Ye SP, Pan SL, Lania G, Matarese F, Saeed S, Di Costanzo A, Belsito Petrizzi V, Ingenito C, Martens JHA, et al: Overexpression of miR-194 reverses HMGA2-driven signatures in colorectal cancer. Theranostics 7: 3889-3900, 2017.

12. Hironaka-Mitsuhashi A, Matsuzaki J, Takahashi RU, Yoshida M, Nezu Y, Yamamoto Y, Shiino S, Kinoshita T, Ushijima T, Hiraoka $\mathrm{N}$, et al: A tissue microRNA signature that predicts the prognosis of breast cancer in young women. PLoS One 12: e0187638, 2017.

13. Ring A, Kim YM and Kahn M: Wnt/catenin signaling in adult stem cell physiology and disease. Stem Cell Rev 10: 512-525, 2014.

14. Lien WH and Fuchs E: Wnt some lose some: Transcriptional governance of stem cells by Wnt/ $\beta$-catenin signaling. Genes Dev 28: 1517-1532, 2014

15. Aminuddin A and Ng PY: Promising druggable target in head and neck squamous cell carcinoma: Wnt signaling. Front Pharmacol 7: 244, 2016

16. Yin D, Jia Y, Yu Y, Brock MV, Herman JG, Han C, Su X, Liu Y and Guo M: SOX17 methylation inhibits its antagonism of Wnt signaling pathway in lung cancer. Discov Med 14: 33-40, 2012

17. Livak KJ and Schmittgen TD: Analysis of relative gene expression data using real-time quantitative PCR and the 2(-Delta Delta C(T)) method. Methods 25: 402-408, 2001.

18. Huo D, Clayton WM, Yoshimatsu TF, Chen J and Olopade OI: Identification of a circulating microRNA signature to distinguish recurrence in breast cancer patients. Oncotarget 7: 55231-55248, 2016.

19. Jung KH, McCarthy RL, Zhou C, Uprety N, Barton MC and Beretta L: MicroRNA regulates hepatocytic differentiation of progenitor cells by targeting YAP1. Stem Cells 34: 1284-1296, 2016.

20. Liu X,Luo M,Xie W,Wells JM, Goodheart MJ and Engelhardt JF: Sox17 modulates Wnt3A/beta-catenin-mediated transcriptional activation of the Lef-1 promoter. Am J Physiol Lung Cell Mol Physiol 299: L694-L710, 2010.
21. Yang H, Lee S, Lee S, Kim K, Yang Y, Kim JH, Adams RH, Wells JM, Morrison SJ, Koh GY and Kim I: Sox17 promotes tumor angiogenesis and destabilizes tumor vessels in mice. J Clin Invest 123: 418-431, 2013.

22. Li Y, Lv Z, He G, Wang J, Zhang X, Lu G, Ren X, Wang F, Zhu X, Ding Y, et al: The SOX17/miR-371-5p/SOX2 ax is inhibits EMT, stem cell properties and metastasis in colorectal cancer. Oncotarget 6: 9099-9112, 2015.

23. Guimarães-Young A, Neff T, Dupuy AJ and Goodheart MJ: Conditional deletion of Sox 17 reveals complex effects on uterine adenogenesis and function. Dev Biol 414: 219-227, 2016.

24. Gao L, Chen B, Li J, Yang F, Cen X, Liao Z and Long X: Wnt $/ \beta$-catenin signaling pathway inhibits the proliferation and apoptosis of U87 glioma cells via different mechanisms. PLoS One 12: e0181346, 2017.

25. Lisanti MP, Tsirigos A, Pavlides S, Reeves KJ, Peiris-Pagès M, Chadwick AL, Sanchez-Alvarez R, Lamb R, Howell A, Martinez-Outschoorn UE and Sotgia F: JNK1 stress signaling is hyper-activated in high breast density and the tumor stroma: Connecting fibrosis, inflammation, and stemness for cancer prevention. Cell Cycle 13: 580-599, 2014.

26. Jang GB, Kim JY, Cho SD, Park KS, Jung JY, Lee HY, Hong IS and Nam JS: Blockade of Wnt/ $\beta$-catenin signaling suppresses breast cancer metastasis by inhibiting CSC-like phenotype. Sci Rep 5: 12465, 2015.

27. Dey N, Barwick BG, Moreno CS, Ordanic-Kodani M, Chen Z, Oprea-Ilies G, Tang W, Catzavelos C, Kerstann KF, Sledge GW Jr, et al: Wnt signaling in triple negative breast cancer is associated with metastasis. BMC Cancer 13: 537, 2013.

28. Liu T, Hu K, Zhao Z, Chen G, Ou X, Zhang H, Zhang X, Wei X, Wang D, Cui M and Liu C: MicroRNA-1 down-regulates proliferation and migration of breast cancer stem cells by inhibiting the Wnt/ $\beta$-catenin pathway. Oncotarget 6: 41638-41649, 2015

29. Yin X, Xiang T, Li L, Su X, Shu X, Luo X, Huang J, Yuan Y, Peng W, Oberst M, et al: DACT1, an antagonist to Wnt/ $\beta$-catenin signaling, suppresses tumor cell growth and is frequently silenced in breast cancer. Breast Cancer Res 15: R23, 2013.

30. Fu D, Ren C, Tan H, Wei J, Zhu Y, He C, Shao W and Zhang J: Sox17 promoter methylation in plasma DNA is associated with poor survival and can be used as a prognostic factor in breast cancer. Medicine (Baltimore) 94: e637, 2015.

31. Manavalan TT, Teng Y, Litchfield LM, Muluhngwi P, Al-Rayyan N and Klinge CM: Reduced expression of miR-200 family members contributes to antiestrogen resistance in LY2 human breast cancer cells. PLoS One 8: e62334, 2013.

32. Zhang G, Zhang W, Li B, Stringer-Reasor E, Chu C, Sun L, Bae S, Chen D, Wei S, Jiao K, et al: MicroRNA-200c and microRNA141 are regulated by a FOXP3-KAT2B axis and associated with tumor metastasis in breast cancer. Breast Cancer Res 19: 73, 2017.

33. Peng Y, Zhang X, Feng X, Fan X and Jin Z: The crosstalk between microRNAs and the Wnt/ $\beta$-catenin signaling pathway in cancer. Oncotarget 8: 14089-14106, 2017.

34. Jia Y, Yang Y, Zhan Q, Brock MV, Zheng X, Yu Y, Herman JG and Guo M: Inhibition of SOX17 by microRNA 141 and methylation activates the WNT signaling pathway in esophageal cancer. J Mol Diagn 14: 577-585, 2012.

This work is licensed under a Creative Commons Attribution-NonCommercial-NoDerivatives 4.0 International (CC BY-NC-ND 4.0) License. 